\title{
Voci dei Caraibi, gli scrittori francofoni d'oltremare, a cura di Alba Pessini
}

\section{Carminella Biondi}

\section{(2) OpenEdition}

10 Journals

\section{Édition électronique}

URL : http://journals.openedition.org/studifrancesi/35296

DOI : $10.4000 /$ studifrancesi.35296

ISSN : 2421-5856

Éditeur

Rosenberg \& Sellier

\section{Édition imprimée}

Date de publication : 1 novembre 2005

Pagination : 455-456

ISSN : 0039-2944

\section{Référence électronique}

Carminella Biondi, « Voci dei Caraibi, gli scrittori francofoni d'oltremare, a cura di Alba Pessini », Studi Francesi [En ligne], 146 (XLIX | II) | 2005, mis en ligne le 30 novembre 2015, consulté le 18 avril 2021. URL : http://journals.openedition.org/studifrancesi/35296 ; DOI : https://doi.org/10.4000/ studifrancesi.35296

Ce document a été généré automatiquement le 18 avril 2021.

\section{(c)}

Studi Francesi è distribuita con Licenza Creative Commons Attribuzione - Non commerciale - Non opere derivate 4.0 Internazionale. 


\title{
Voci dei Caraibi, gli scrittori francofoni d'oltremare, a cura di Alba Pessini
}

\author{
Carminella Biondi
}

\section{RÉFÉRENCE}

Voci dei Caraibi, gli scrittori francofoni d'oltremare, a cura di Alba Pessini, «Palazzo

Sanvitale», n. 12/2004, Parma, Monte Università editore, pp. 255.

1 Cette très belle anthologie d'écrivains des Antilles francophones est un de ces volumes que l'on souhaite posséder dans sa propre bibliothèque, car il s'agit avant tout d'un texte fort soigné du point de vue formel, qui charme grâce à un choix d'illustrations qui nous conduisent aux origines de la découverte de ces terres et nous aident à situer géographiquement et historiquement les récits proposés, grâce aux portraits de Roberto Meli, qui ont su saisir les caractéristiques des auteurs bien au-delà d'une simple ressemblance physique. Mais si nous dépassons l'aspect visuel et iconographique qui a son importance, la logique du choix des textes, la clarté avec laquelle ils sont introduits, la réussite des traductions en italien, laissent entrevoir la présence d'une main savante qui a su orienter et guider ce travail d'ensemble, en grande partie tiré de «tesi di laurea», présentées à l'Université de Parme. Et nous rencontrons ce guide en ouverture de l'ouvrage, après l'éditorial qui revendique, à juste titre, l'originalité de l'entreprise et qui souligne combien le désir de prêter une attention particulière à la nouveauté, aux marges, a présidé à la réalisation de ce volume. Alba Pessini, qui a dirigé cette publication, trace un panorama historicoculturel de l'aire caraïbe francophone où sont reconstruits les événements marquants et les étapes d'un difficile voyage, non seulement vers la conquête de l'indépendance, mais aussi et surtout vers la conquête progressive d'une identité permettant de sortir de l'aphasie, de faire émerger de l'obscurité la «parole de nuit» qui serait enfin en mesure de raconter l'Histoire et les histoires de ces peuples privés de passé. Le nœud central de cette reconstruction est, à juste titre, Haïti qui a été la première république noire indépendante, un symbole et, entre autres, une référence pour les peuples noirs 
du monde entier, même si aujourd'hui, à cause des malheurs qui l'ont frappée, elle représente un modèle social et politique négatif. Les auteurs traduits sont les haïtiens Émile Ollivier, Louis-Philippe Dalembert et Yanick Lahens, respectivement présentés par Maddalena Battistini, Monica Blondi, Manuela Massari, et les martiniquais Raphaël Confiant et Édouard Glissant, présentés par Miriam Venturini et Luca Bonali. Le choix des auteurs, tout en étant très sélectif, reconstruit bien dans son ensemble le tableau des typologies d'écriture de cette aire: l'écriture de l'exil, «du dehors» d'ollivier et Dalembert, l'écriture des créateurs qui ont choisi de rester dans leur île, l'écriture du «dedans», de Lahens, la transposition du conte oral, de Confiant, et l'écriture de la créolisation et du Tout-monde de Glissant. À travers ce dernier auteur l'archipel des Caraïbes réalise sa vocation d'ouverture sur le monde auquel, en vertu d'une expérience de croisements culturels et ethniques qui se sont multipliées au cours des siècles, les îles qui font face aux Amériques ont peut-être quelque chose à dire.

Émile Ollivier ouvre l'anthologie avec une nouvelle intitulée Regarde, regarde les lions. Ce titre fort, très poétique, qui évoque des horizons lointains, semble vouloir nous conduire sur les routes du rêve mais nous plonge en réalité brutalement dans l'existence d'un pauvre diable, du nom de Manès, alter ego de l'écrivain, qui pour survivre doit faire toutes sortes de métiers. Il va jusqu'à devoir se feindre lion dans un cirque, au risque de mourir de peur quand, précipité dans l'arène, il se trouve nez à nez avec un lion, à l'apparence féroce. Il découvrira par la suite qu'il s'agit en réalité d'un autre pauvre hère qui, comme lui, n'a fait que fort bien interpréter son rôle. Cette reconstitution dramatique de la vie d'un jeune haïtien émigré est placée sous le signe de la poésie mais aussi du grotesque et de l'ironie. Nous retrouvons ce mélange des tons, qui est d'ailleurs souvent la marque des écritures des Caraïbes, dans les deux récits qui suivent, signés Louis-Philippe Dalembert. J'évoquerai le premier, Frontières interdites, où l'auteur conjugue, de façon particulièrement raffinée, son goût pour une écriture érotique assez poussée et le sens tragique de l'existence, et repropose dans une version originale le binôme amour et mort, maintes fois traité en littérature. La tragédie, annoncée par un souvenir d'enfance, le souvenir d'un enfant qui poussé par le désir de cueillir un beau fruit tombe d'un arbre, s'accomplit légère et banale comme le plus commun des gestes quotidiens, à la fin du récit, parce que la tragédie fait justement partie du quotidien d'Haïti. Avec Yanick Lahens nous entrons dans le monde d'une double marginalité: celle de tout le peuple haïtien sur sa terre qui ne lui offre que misère et violence et celle des femmes. La protagoniste n'a d'autre issue, à la fin de l'histoire, que l'emploi de son très beau corps pour sortir de la misère, de la «banalité quotidienne du désastre». Mais le prix à payer est très élevé: «Assise au bord de la baignoire, elle pensa aux rues nauséabondes, à Wilfrid, aux murs lambrissés, aux privations puis à une maison entourée d'un jardin, aux enfants aux cheveux et à la peau aux couleurs des vainqueurs que William lui ferait peut-être dans l'ohio ou dans le Wisconsin. Elle ravala sa légère nausée tout au fond de sa gorge. Quand elle quitta les toilettes, Mirna souriait et portait déjà ce masque qui devait remplacer son visage le reste de sa vie» (p. 132). Pour les fils d'Haïti, qui surent les premiers sortir vainqueurs de l'affrontement avec l'écrasant pouvoir colonial, il semble n'y avoir aujourd'hui aucun espoir de salut. Le ton devient plus léger avec les récits qui suivent, les contes populaires rassemblés par le martiniquais Raphaël Confiant, qui rappellent un peu nos fabliaux médiévaux, où la ruse se conjugue souvent à une morale quelque peu désabusée et cruelle. La conclusion du volume est confiée, à juste titre, au plus grand des écrivains caraïbes, à Édouard Glissant qui, au-delà des étiquettes, est une figure 
imposante de la littérature de notre temps. L'extrait qui est proposé pour le présenter aux lecteurs italiens nous paraît un bon choix. Il s'agit du premier chapitre du roman Tout-monde, paru en 1993, chapitre entièrement situé en Italie où l'écrivain a vécu pendant quelques mois au cours de sa jeunesse. L'Italie, c'est à dire Gênes, ce port mythique qui marque le point de départ idéal des voyages de la Conquête, où le jeune auteur accomplit une sorte de pèlerinage vers le lieu dans lequel tout commença. Cette belle anthologie me paraît avoir le mérite de conjuguer l'initiation à la connaissance d'un univers au plaisir du texte. 